\title{
Diseño De Un Producto Agro-Ecoturístico En La Propiedad De La Empresa Agropecuaria Y Turística “A Y T” Parroquia San Isidro, Cantón Guano, Provincia De Chimborazo
}

\section{Guicela Margoth Ati Cutiupala}

Ingeniera en Ecoturismo - Facultad de Recursos Naturales

ESCUELA SUPERIOR POLITÉCNICA DE CHIMBORAZO - ECUADOR

\section{Juan Carlos Carrasco Baquero}

Docente - Investigador de la Facultad de Recursos Naturales

ESCUELA SUPERIOR POLITÉCNICA DE CHIMBORAZO - ECUADOR

\section{Paola Alexandra Velastegui Arévalo}

Bioquímica Farmacéutica, Facultad de Ciencias

ESCUELA SUPERIOR POLITÉCNICA DE CHIMBORAZO - ECUADOR

\section{Sofía Andrea Basantes Vinueza}

Ingeniera en Ecoturismo - Facultad de Recursos Naturales

ESCUELA SUPERIOR POLITÉCNICA DE CHIMBORAZO - ECUADOR

\section{Carlos Renato Chávez Velásquez}

Docente - Investigador de la Facultad de Recursos Naturales

ESCUELA SUPERIOR POLITÉCNICA DE CHIMBORAZO - ECUADOR

Ingeniera en Ecoturismo - Facultad de Recursos Naturales

ESCUELA SUPERIOR POLITÉCNICA DE CHIMBORAZO - ECUADOR

Bioquímica Farmacéutica, Facultad de Ciencias

ESCUELA SUPERIOR POLITÉCNICA DE CHIMBORAZO - ECUADOR Tecnólogo en Construcciones Andinas - Escuela de Construcciones Andinas

- INSTITUTO SUPERIOR "JATUN YACHAY WASI" COLTA ECUADOR

doi: 10.19044/esj.2016.v12n32p146 URL:http://dx.doi.org/10.19044/esj.2016.v12n32p146

\begin{abstract}
The development of an agro-ecotourism product in the A\&T Agricola and touristic company was the objective of this research project. The first stage of this project consisted in the collection of primary and secondary information through field visits and literature review. It was identified that local and international tourist will be the target audience of this product (target demand). Furthermore, a complete inventory of touristic sites in the zone were created. This inventory identified five natural
\end{abstract}


attractions and five cultural attractions, with five attractions reaching level II of hierarchy. To target tourist, four packages were designed using touristic and agro-ecological activities. In the second stage of this project, economic, legal, and environmental feasibility analyses will be performed. Finally, the agro-ecotourism product proposed in this project is an alternative for the development of the local population as it takes into account the local agriculture in conjunction with ecological activities targeted to the improvement of the society economically and culturally.

Keywords: Agro-ecotourism, environmental impact, agro-ecologic production

\section{Resumen}

La presente investigación propone: realizar el diseño de un producto agro-ecoturístico en la propiedad de la empresa Agropecuaria y Turística “A y T”, en una primera etapa mediante la recopilación de información primaria y secundaria con salidas de campo y revisiones bibliográficas, se determinó el mercado de turistas nacionales y extranjeros los cuales serán la demanda objetivo. Posteriormente se elaboró el inventario de atractivos turísticos, el cual identifica 5 atractivos correspondientes a la categoría sitios naturales y 5 atractivos de categoría manifestaciones culturales, siendo 5 atractivos los que alcanzan jerarquía II. En función del perfil del turista se diseñaron 4 paquetes que contemplan actividades turísticas y agroecológicas. Los estudios de factibilidad, legal, ambiental y económico - financiero se presentaran en la segunda fase del proyecto. Finalmente este producto turístico se plantea como una alternativa para el desarrollo local de la población, aprovechando su potencial agropecuario y permitiendo la factibilidad de realizar actividades ecológicas en busca de un mejor ambiente para la sociedad tanto económica, social y culturalmente.

Palabras clave: Agroturismo de comercialización, impacto ambiental, producción agroecológica.

\section{Introducción}

El turismo crece anualmente a escala mundial, así como en regiones del continente americano por encima de lo estimado, esto lo demuestran las cifras de acuerdo al barómetro de turismo 2016 de la OMT, que se estimaba un crecimiento del 5\% para el primer trimestre del año, sin embargo a finales del semestre se evaluó un crecimiento del 7\%, siendo Estado Unidos el país emisor de la mayor cantidad de turistas que viajan a nivel internacional con aproximadamente 500 millones de visitantes (UNWTO, 2016). Por lo que los organismos o entes competentes deben adaptarse a los cambios $\mathrm{y}$ 
planificar el crecimiento sostenible del turismo, así lo hace la OMT que promueve políticas e instrumentos para el análisis de esta actividad, aboga además por un turismo que contribuya al progreso económico, un desarrollo incluyente y a la sostenibilidad ambiental.

Los países de Sur América demuestran un gran interés por mejorar sus destinos turísticos, proyectándolos de manera sustentable y amigable con el medio ambiente, además de ser conocidos como “destinos verdes” por su notable geografía, estos destinos no se encuentran en su totalidad explotados y se disponen con mejores propuestas ambientales para el desarrollo integral de sus habitantes (Moreno y Coromoto, 2010). Entre las nuevas tendencias del turismo, el consumidor busca tener una experiencia más cercana con la naturaleza y lo rural (Ávila y Barrado, 2005).

El Ecuador articula dichas premisas en su Plan Estratégico de Desarrollo de Turismo Sostenible (PLANDETUR 2020), donde identifica 11 líneas de productos y sus variedades específicas, de los cuales el producto agroturismo fue uno de los prioritarios y potenciales. El agroturismo efectivamente puede convertirse en una actividad complementaria de las actividades agrícolas que realiza el pequeño productor, con la ventaja de que éste percibe una retribución por la conservación de su hábitat y, por ende, mejora su calidad de vida (SENPLADES, 2016).

De acuerdo con el Plan Nacional del Buen Vivir 2014-2017 que enuncia en su objetivo número 10: Impulsar la transformación de la matriz productiva del país; y que para lograr su propósito crea políticas como la 10.4 y 10.6 que son el marco legal de apoyo a los emprendimientos y microempresas, que menciona lo siguiente: "Impulsar la producción y la productividad de forma sostenible y sustentable, fomentar la inclusión y redistribuir los factores y recursos de la producción en el sector agropecuario, acuícola y pesquero; potenciar procesos comerciales diversificados y sostenibles en el marco de la transformación productiva, respectivamente"(SENPLADES, 2016).

El Ecuador al ser un país agricultor mayoritariamente, se proyecta a través de las políticas públicas a cambiar el modelo de la matriz productiva, mejorando los procesos productivos y sustituyendo la extracción de los recursos no renovables como el petróleo, por aquellos ingresos que se generan por el concepto de turismo (SENPLADES, 2016). Como aliado estratégico, el ecoturismo es uno de los productos más vinculados al territorio ecuatoriano, por poseer 51 áreas naturales conservadas, que abarcan el 20\% del territorio nacional (MAE, 2016), además de ser una modalidad que se practica con éxito en muchas partes del mundo como Costa Rica y Estados Unidos (Molina, 2004).

La modalidad de turismo conocida como agroturismo consiste en viajar al campo para aprender sobre prácticas tradicionales de cultivos, 
cosechas y procesamiento de productos agropecuarios, forestales y pesqueros, además de la artesanía y la cultura local (Riveros y Blanco, 2003), considerando los nuevos retos en preferencias de la demanda actual, se adapta el agroecoturismo en el país de Costa Rica inicialmente, donde en la actualidad ya cuentan con un modelo de gestión para esta actividad en específico. Zumbado (2007) menciona que, bajo los tres ejes de desarrollo sostenible los cuales son social, económico y ambiental, esta práctica interrelaciona el agroturismo con el ecoturismo, en busca de ofertar servicios que satisfagan las necesidades del visitante sin comprometer las necesidades de generaciones futuras (Vidal, 2004).

Una de las ventajas del agroturismo es que las compras de productos alimenticios se hacen en la misma granja, o en otras vecinas, de modo que la demanda económica favorece directamente a la comunidad productora, sin embargo para Budowski (2001), acota que el principal obstáculo para el desarrollo del agroturismo es la carencia de personal entrenado para interpretar de forma atractiva y con suficientes conocimientos científicos, como también la disponibilidad de los productos agrarios debido a que el cultivo no sea perenne.

Se presenta así un nuevo reto en la investigación, el de consolidar el agroecoturismo como un producto turístico competitivo para la demanda nacional e internacional (Cárdenas, 2004). Se debe crear un buen diseño, resultado de una combinación adecuada de elementos tangibles e intangibles como atractivos, equipamientos, infraestructuras, servicios, actividades recreativas y valores simbólicos que brinden beneficios capaces de atraer a grupos determinados de consumidores (Crosby y Moreda, 1996).

El cantón Guano, localizado en el callejón interandino, posee grandes extensiones de terrenos aptos para la agricultura y ganadería, en donde existe variedad de cultivos como: papas, habas, maíz, mora entre otros, además las prácticas culturales aún están arraigadas entre sus pobladores, lo que constituye la base para desarrollar nuevos emprendimientos alternativos como el agroecoturismo. Entre sus parroquias se encuentra San Isidro, se destaca por la práctica de la agroecología, por la diversidad de cultivos y por el aporte en el cambio de la matriz productiva.

Entonces el agroecoturismo como una herramienta de desarrollo integral impulsa la economía de los agricultores ya que integra las actividades tradicionales de producción como la agricultura y ganadería: a lo que se pretende incorporar la actividad alternativa del agroecoturismo con lo que se mejorará la economía de una forma sostenible, impulsando los cultivos sanos, eficientes, rentables y competitivos y al mismo tiempo se genera satisfacción en los posibles visitantes (Blanco y Riveros, 2010). 


\section{Metodología}

En el presente estudio se aplicó técnicas de investigación bibliográfica (secundaria) y de campo (primaria), de manera explorativa, descriptiva y analítica; los cuales se detallan a continuación:

\section{- $\quad$ Evaluar el potencial turístico de la parroquia San Isidro}

\section{Diagnóstico Situacional}

Se revisó y recopilo información mediante el análisis y sistematización de los planes de desarrollo cantonal, provincial y parroquial disponibles en el gobierno provincial, Asociación de Gobiernos Parroquiales e instituciones involucradas con este sector, complementándose con información primaria obtenida de entrevistas a los habitantes del sector. La información se sistematizó y ordeno acorde al diagnóstico estrella propuesto por Tierra (2012), en los siguientes ámbitos: físico espacial, socio cultural, ecológico territorial, económico productivo y socio cultural.

\section{Inventario de los atractivos turísticos}

Se realizaron salidas de campo en los cuales la herramienta que se utilizó es la ficha para inventariar atractivos turísticos propuesta por el MINTUR (2004), luego se procedió a georeferenciar, valorar, evaluar y jerarquizar cada atractivo.

En cuanto al inventario de recursos culturales se procedió a emplear la metodología propuesta por el Instituto Nacional de Patrimonio Cultural (INPC, 2011), utilizando las fichas de registro del patrimonio inmaterial de acuerdo a los parámetros establecidos en el "Instructivo para Fichas de Registro e Inventario del Patrimonio Cultural Inmaterial”. Consta de: a) Tradiciones y expresiones orales, b) Artes del espectáculo, c) Usos sociales, rituales y actos festivos, d) Conocimientos y usos relacionados con la naturaleza y el universo, e) Técnicas artesanales tradicionales.

\section{- $\quad$ Estudio de mercado}

Demanda

Para el estudio de la demanda se identificó y segmento el universo tomando en cuenta las variables geográficas, psicológicas y motivacionales, los mismos que fueron orientados a identificar las preferencias de los actuales y potenciales visitantes.

Se definió el universo de estudio conformado por los turistas que visitan el cantón Guano en el año 2012 en dos grupos fundamentales desde el sector turístico que son los visitantes nacionales y extranjeros.

El número de turistas que se consideraron para proyectar la demanda son aquellos que visitaron el cantón Guano en el año 2012 que de acuerdo a los datos oficiales del Municipio del cantón fueron 80000 turistas de los cuales aproximadamente el $70 \%$ es decir 56000 son nacionales y el 30\% que 
representa 24000 son extranjeros, de acuerdo a la proyección para el 2014 serán 102152 turistas, de los cuales 71506 (70\%) son nacionales y 30646 (30\%) son turistas extranjeros

Mediante la aplicación de la fórmula de Cannavos se calculó el tamaño de la muestra y se procedió a aplicar una encuesta, partiendo de un cuestionario que permitió conocer las características socio-demográficas y psicográficas de la población objetivo.

La fórmula se detalla a continuación:

$$
n=\frac{N * P * Q}{(N-1) *(e / z)^{2}+P^{*} Q}
$$

Donde:

$\mathbf{n}=$ tamaño de la muestra

$\mathbf{N}=$ universo de estudio (102152)

$\mathbf{e}=$ margen de error $(0,08)$

$\mathbf{z}=$ nivel de confiabilidad $96 \%(1,75)$

$\mathbf{p}=$ probabilidad de ocurrencia $(0,5)$

$\mathbf{q}=$ probabilidad de no ocurrencia $(0,5)$

La muestra obtenida fue de 119 y corresponde al número total de encuestas de las cuales 83 están dirigidas a los turistas nacionales y 36 a turistas extranjeros.

Para la tabulación de los resultados se realizó mediante la aplicación del paquete estadístico Statistical Package for the Social Sciences (SPSS); posteriormente se realizó el análisis de resultados.

\section{Oferta}

Se identificó y caracterizo la competencia, oferta actual y oferta complementaria para la cual se procedió a realizar un análisis de la zona con prestadores de servicios turísticos que realicen actividades relacionadas con el Agroturismo. Se tomó en cuenta datos esenciales como: ubicación, años de funcionamiento, servicios e instalaciones, tipo de visitantes, número de visitantes anuales, precio, publicidad y promoción.

Confrontación oferta - demanda

Para las proyecciones se utilizó el método de Incremento Compuesto descrito a continuación:$$
\operatorname{Cn}=\operatorname{Co}(\mathbf{1}+\mathbf{i})^{\mathrm{n}}
$$
Donde:
$\mathbf{C n}=$ incremento compuesto
$\mathbf{C o}=$ número de turistas potenciales
$\mathbf{i}=\quad$ índice de crecimiento turístico o poblacional
$\mathbf{n}=$ años a proyectar 
Proyección de la demanda: Para la proyección de la demanda se fusionó los valores de los turistas nacionales y extranjeros, tomando como base el porcentaje de aceptación del proyecto en las encuestas.

Proyección de la oferta: Se proyectó para los cinco años posteriores al proyecto que permitirán determinar el abastecimiento del mercado, se utilizó el método del incremento compuesto.

Demanda potencial insatisfecha: Se aplicó la siguiente formula: $D P I=D-O$

Donde:

DPI = demanda potencial insatisfecha

$\mathbf{D}=$ demanda

$\mathbf{O}=$ oferta

Determinación de la cuota objetivo: Permitió realizar una aproximación para delimitar el tamaño del proyecto, en esta fase se proyectó los servicios de preferencia y actividades.

- Diseño del producto turístico

Para el diseño técnico fue esencial revisar el diagnóstico y el inventario de atractivos turísticos para seleccionar los atractivos que poseen jerarquías de alto rango, de igual manera se analizó las condiciones actuales de los elementos del sistema turístico.

\section{- $\quad$ Estudio técnico del producto}

Se contempló: lineamientos básicos para el diseño de la estructura de la granja integral ecoturística, procesos sustentables para el desarrollo de las actividades en la granja integral ecoturística, identificación de los requerimientos de infraestructura y facilidades turísticas, estructuración de paquetes que contemplen circuitos turísticos entre otros elementos complementarios del diseño técnico

\section{Resultados}

- Inventario de recursos naturales y culturales

Cuadro 1. Matriz resumen de los atractivos turísticos naturales y culturales materiales de la parroquia San Isidro

\begin{tabular}{|c|c|c|c|c|c|}
\hline$\#$ & $\begin{array}{c}\text { Nombre del } \\
\text { atractivo }\end{array}$ & Categoría & Tipo & Subtipo & Jerarquía \\
\hline 1 & $\begin{array}{c}\text { Iglesia de San } \\
\text { Isidro }\end{array}$ & $\begin{array}{c}\text { Manifestaciones } \\
\text { culturales } \\
\text { Históricas }\end{array}$ & Históricas & $\begin{array}{c}\text { Arquitectura } \\
\text { religiosa }\end{array}$ & II \\
\hline 2 & $\begin{array}{c}\text { Sembrío de mora } \\
\text { cultivado } \\
\text { agroecológicamente }\end{array}$ & $\begin{array}{c}\text { Manifestaciones } \\
\text { culturales }\end{array}$ & $\begin{array}{c}\text { Manifestaciones } \\
\text { religiosas, } \\
\text { tradiciones y } \\
\text { creencias. }\end{array}$ & $\begin{array}{c}\text { Prácticas } \\
\text { agrícolas } \\
\text { tradicionales }\end{array}$ & II \\
\hline 3 & $\begin{array}{c}\text { Cascadas de San } \\
\text { Isidro }\end{array}$ & Sitios naturales & Rio & Cascadas & II \\
\hline
\end{tabular}




\begin{tabular}{|c|c|c|c|c|c|}
\hline 4 & $\begin{array}{c}\text { Mirador de San } \\
\text { Isidro }\end{array}$ & Sitios naturales & Montaña & Mirador & I \\
\hline 5 & Mirador de Tembo & Sitios naturales & Montaña & Mirador & I \\
\hline 6 & Casa ecológica & $\begin{array}{c}\text { Manifestaciones } \\
\text { culturales }\end{array}$ & $\begin{array}{c}\text { Realizaciones } \\
\text { técnicas y } \\
\text { científicas }\end{array}$ & $\begin{array}{c}\text { Estilo de } \\
\text { Construcción }\end{array}$ & I \\
\hline 7 & $\begin{array}{c}\text { Reservorio de } \\
\text { Truchas }\end{array}$ & $\begin{array}{c}\text { Manifestaciones } \\
\text { culturales }\end{array}$ & $\begin{array}{c}\text { Realizaciones } \\
\text { técnicas y } \\
\text { científicas }\end{array}$ & $\begin{array}{c}\text { Explotación } \\
\text { piscícola }\end{array}$ & I \\
\hline 8 & Río Patulú & Sitio natural & Río & Riachuelo & I \\
\hline 9 & Río Guano & Sitio natural & Río & Riachuelo & II \\
\hline 10 & Páramo de Igualata & Sitios naturales & Montaña & Páramo & II \\
\hline
\end{tabular}

Cuadro 2. Matriz resumen de atractivos culturales inmateriales de la parroquia San Isidro

\begin{tabular}{|c|c|c|c|c|}
\hline$\#$ & Denominación & Ámbito & Subámbito & Detalle del Subámbito \\
\hline 1 & $\begin{array}{c}\text { Práctica ancestral del } \\
\text { cambiamanos }\end{array}$ & $\begin{array}{c}\text { Usos sociales rituales y } \\
\text { actos festivos }\end{array}$ & $\begin{array}{c}\text { Práctica de } \\
\text { prestamanos para } \\
\text { ciertas actividades }\end{array}$ & $\begin{array}{c}\text { Practica relacionada a la } \\
\text { vida cotidiana }\end{array}$ \\
\hline 2 & $\begin{array}{c}\text { Gastronomía } \\
\text { cotidiana- Santa } \\
\text { Lucia de Tembo }\end{array}$ & $\begin{array}{c}\text { Conocimientos y usos } \\
\text { relacionados con la } \\
\text { naturaleza y el universo }\end{array}$ & Gastronomía & Gastronomía cotidiana \\
\hline 3 & $\begin{array}{c}\text { Leyenda del duende } \\
\text { orales }\end{array}$ & $\begin{array}{c}\text { Tradiciones y expresiones } \\
\text { oeyendas }\end{array}$ & $\begin{array}{c}\text { Leyendas asociadas a } \\
\text { apariciones de seres } \\
\text { sobrenaturales }\end{array}$ \\
\hline 4 & $\begin{array}{c}\text { Práctica ancestral de } \\
\text { la minga }\end{array}$ & $\begin{array}{c}\text { Usos sociales rituales y } \\
\text { actos festivos }\end{array}$ & Práctica agrícola & $\begin{array}{c}\text { Costumbres de la vida } \\
\text { cotidiana de la } \\
\text { población }\end{array}$ \\
\hline 5 & Parteras & $\begin{array}{c}\text { Conocimientos y usos } \\
\text { relacionados con la } \\
\text { naturaleza y el universo }\end{array}$ & $\begin{array}{c}\text { Medicina } \\
\text { tradicional }\end{array}$ & N/A \\
\hline
\end{tabular}

\section{- $\quad$ Estudio de mercado}

\section{Análisis de la oferta turística}

Cuadro 3. Información sobre competidores

\begin{tabular}{|c|c|c|c|}
\hline Nombre & Ubicación & Servicios & Actividades \\
\hline $\begin{array}{l}\text { Hostería boutique y } \\
\text { finca orgánica } \\
\text { Ecovita }\end{array}$ & $\begin{array}{l}\text { Pallatanga Km } \\
139 \text { Vía Gye- } \\
\text { Riobamba }\end{array}$ & $\begin{array}{c}\text { Alojamiento } \\
\text { Alimentación } \\
\text { Guianza }\end{array}$ & $\begin{array}{c}\text { Camping } \\
\text { Senderismo } \\
\text { Practicas Agroecológicas } \\
\text { Observación de flora y } \\
\text { fauna } \\
\text { Observación de aves }\end{array}$ \\
\hline $\begin{array}{c}\text { Granja agro turística } \\
\text { Totorillas }\end{array}$ & $\begin{array}{l}\text { Sector Mushuj } \\
\text { Ayllu, } \\
\text { Comunidad } \\
\text { Sablog Chico, } \\
\text { parroquia } \\
\text { Matriz, cantón } \\
\text { Guamote }\end{array}$ & $\begin{array}{l}\text { Alojamiento } \\
\text { Alimentación } \\
\text { Guianza } \\
\text { Sala de eventos y } \\
\text { recepciones }\end{array}$ & $\begin{array}{c}\text { Camping } \\
\text { Senderismo } \\
\text { Practicas Agroecológicas } \\
\text { Observación de flora y } \\
\text { fauna } \\
\text { Observación de aves }\end{array}$ \\
\hline
\end{tabular}




\section{Proyección de la oferta}

Para el análisis de la competencia se recurrió al dato de los turistas que han visitado la hostería Ecovita (2210) y la granja Totorillas (8661) en el año 2014.

Cuadro 4. Proyección de la competencia

\begin{tabular}{|c|c|}
\hline \multicolumn{2}{|c|}{ PROYECCIÓN COMPETENCIA } \\
\hline Año & Proyección \\
\hline 2014 & 10871 \\
\hline 2015 & 12284 \\
\hline 2016 & 13881 \\
\hline 2017 & 15686 \\
\hline 2018 & 17725 \\
\hline 2019 & 20029 \\
\hline 2020 & 22633 \\
\hline
\end{tabular}

- $\quad$ Análisis de la demanda turística

La muestra se obtuvo del universo y luego mediante la estratificación se determinó el número de encuesta a aplicarse para cada segmento.

Distribución de encuestas: La muestra que se obtuvo fue de 119 de las cuales, 83 fueron dirigidas a turistas nacionales y 36 a turistas extranjeros. Se utilizó como instrumento una encuesta de opción múltiple aplicada a turistas de habla hispana y haba inglesa.

\section{Edad}

Tabla $\mathbf{N}^{\mathbf{0}} \mathbf{1}$. Rango de edad de los turistas nacionales y extranjeros

\begin{tabular}{|c|c|c|c|c|c|}
\hline \multicolumn{2}{|c|}{ Turistas nacionales } & \multicolumn{2}{c|}{ Turistas extranjeros } \\
\hline Variables & $\mathrm{N}^{\circ}$ & $\%$ & Variables & $\mathrm{N}^{\circ}$ & $\%$ \\
\hline Menos de 18 años & 7 & $8 \%$ & Menos de 18 años & 3 & $8 \%$ \\
\hline Entre 18 y 25 años & 23 & $28 \%$ & Entre 18 y 25 años & 3 & $8 \%$ \\
\hline Entre 26 y 40 años & 28 & $34 \%$ & Entre 26 y 40 años & 12 & $33 \%$ \\
\hline Más de 40 años & 25 & $30 \%$ & Más de 40 años & 18 & $50 \%$ \\
\hline Total & 83 & $100 \%$ & & 36 & $100 \%$ \\
\hline
\end{tabular}

De los turistas nacionales el 34\% comprende edades entre los 26-40 años, seguido por más de 40 años el $30 \%$, de $18-25$ años el $28 \%$, mientras que los menores de 18 años el 8\%. En cuanto a los turistas extranjeros se determinó que, el rango de edad de más de 40 años es el más alto porcentaje con 50\%, seguido por el de 26-40 años con el 33\%, los menores de 18 años y los que tienen entre 18 y 25 tienen el $8 \%$ respectivamente. Esto indica que las actividades a realizarse deben estar orientadas a personas de estos rangos de edad. 
Género

Tabla $\mathbf{N}^{\mathbf{0}} 2$. Género de los turistas nacionales y extranjeros

\begin{tabular}{|c|c|c|c|c|c|}
\hline \multicolumn{3}{|c|}{ Turista nacional } & \multicolumn{3}{c|}{ Turista extranjero } \\
\hline Variables & $\mathrm{N}^{\circ}$ & $\%$ & Variables & $\mathrm{N}^{\circ}$ & $\%$ \\
\hline Masculino & 48 & $58 \%$ & Masculino & 19 & $53 \%$ \\
\hline Femenino & 35 & $42 \%$ & Femenino & 17 & $47 \%$ \\
\hline Total & 83 & $100 \%$ & Total & 36 & $100 \%$ \\
\hline
\end{tabular}

El 58\% de los turistas nacionales son de género masculino, mientras que el $42 \%$ es de género femenino. El porcentaje de variación con respecto al género del turista extranjero determinó que el $53 \%$ son de género masculino y el $47 \%$ femenino.

\section{Procedencia}

Tabla $\mathbf{N}^{\mathbf{3}}$ 3. Procedencia de los turistas nacionales y extranjeros

\begin{tabular}{|c|c|c|c|c|c|}
\hline \multicolumn{3}{|c|}{ Turistas nacionales } & \multicolumn{3}{|c|}{ Turistas extranjeros } \\
\hline Variables & $\mathrm{N}^{\mathrm{o}}$ & $\%$ & Variables & $\mathrm{N}^{\mathrm{o}}$ & $\%$ \\
\hline Ambato & 6 & 7 & Estados Unidos & 6 & 17 \\
\hline Azogues & 4 & 5 & Bolivia & 2 & 6 \\
\hline Guaranda & 2 & 2 & Chile & 2 & 6 \\
\hline Guayaquil & 27 & 33 & Colombia & 2 & 6 \\
\hline Loja & 2 & 2 & Alemania & 6 & 17 \\
\hline Puyo & 2 & 2 & España & 14 & 39 \\
\hline Quevedo & 2 & 2 & Italia & 4 & 11 \\
\hline Quito & 10 & 12 & & & \\
\hline Riobamba & 22 & 27 & & & \\
\hline Santo Domingo & 4 & 5 & & & \\
\hline Tena & 2 & 2 & & & \\
\hline Total & 83 & 100 & Total & 36 & 100 \\
\hline
\end{tabular}

En los resultados obtenidos de la encuesta se determinó que la procedencia de los turistas nacionales es de Guayaquil el 33\%, Riobamba el 27\%, Quito el 12\% mientras que de las ciudades de Tena, Quevedo, Puyo, Loja y Guaranda con el 2\%. Mediante la encuesta formulada para determinar la procedencia de los turistas extranjeros se evidenció que el 39\% son de España, seguido por el $17 \%$ que son de Alemania y Estados Unidos respectivamente, el $11 \%$ de Italia y finalmente el $6 \%$ son de Bolivia, Chile y Colombia respectivamente.

\section{Nivel de instrucción}

Tabla N4. Nivel de instrucción de los turistas nacionales y extranjeros

\begin{tabular}{|c|c|c|c|c|c|}
\hline \multicolumn{3}{|c|}{ Turista nacional } & \multicolumn{3}{c|}{ Turista extranjero } \\
\hline Variables & $\mathrm{N}^{\circ}$ & $\%$ & Variables & $\mathrm{N}^{\circ}$ & $\%$ \\
\hline Doctorado & 5 & $6 \%$ & Doctorado & 2 & $6 \%$ \\
\hline Postgrado & 16 & $19 \%$ & Posgrado & 12 & $33 \%$ \\
\hline Superior & 51 & $61 \%$ & Superior & 13 & $36 \%$ \\
\hline Secundaria & 11 & $14 \%$ & Secundaria & 9 & $25 \%$ \\
\hline Total & 83 & $100 \%$ & Total & 36 & $100 \%$ \\
\hline
\end{tabular}


A través de la encuesta realizada a los turistas nacionales se evidencia que el nivel de educación o instrucción liderada por la formación superior con el 61\%, seguida por el posgrado con 19\%, la secundaria con el $14 \%$ y el doctorado es representado con el 6\%. Los turistas extranjeros encuestados tiene los siguientes resultados, el nivel de educación con el porcentaje más alto es el superior con un $36 \%$, el $33 \%$ son de postgrado, el $25 \%$ de la secundaria y finalmente el 6\% de doctorado.

\section{Motivo de viaje}

Tabla $\mathbf{N}^{\circ}$. Motivo de viaje de los turistas nacionales y extranjeros

\begin{tabular}{|c|c|c|c|c|c|}
\hline \multicolumn{3}{|c|}{ Turista nacional } & \multicolumn{3}{c|}{ Turista extranjero } \\
\hline Variables & $\mathrm{N}^{\circ}$ & $\%$ & Variables & $\mathrm{N}^{\circ}$ & $\%$ \\
\hline Distracción & 80 & $96 \%$ & Distracción & 32 & $88 \%$ \\
\hline Trabajo & 3 & $4 \%$ & Estudios & 2 & $6 \%$ \\
\hline \multicolumn{2}{|c|}{} & & Trabajo & 2 & $6 \%$ \\
\hline Total & 83 & $100 \%$ & Total & 36 & $100 \%$ \\
\hline
\end{tabular}

A partir de las encuestas aplicadas se aprecia que el motivo de viaje del turista nacional es el $96 \%$ por distracción y el $4 \%$ por trabajo. El motivo por el cual generalmente viajan los turistas extranjeros son el $88 \%$ por distracción y el $6 \%$ por estudios y trabajo respectivamente.

\section{Acompañantes de viaje}

Tabla $\mathbf{N}^{\mathbf{0}} \mathbf{6}$. Acompañantes de viaje de los turistas nacionales y extranjeros

\begin{tabular}{|c|c|c|c|c|c|}
\hline \multicolumn{3}{|c|}{ Turista nacional } & \multicolumn{3}{c|}{ Turista extranjero } \\
\hline Variables & $\mathrm{N}^{\circ}$ & $\%$ & Variables & $\mathrm{N}^{\circ}$ & $\%$ \\
\hline Amigos & 27 & $33 \%$ & Amigos & 24 & $67 \%$ \\
\hline Familia & 42 & $51 \%$ & Familia & 8 & $22 \%$ \\
\hline Pareja & 10 & $12 \%$ & Pareja & 2 & $6 \%$ \\
\hline Solo & 4 & $5 \%$ & Solo & 2 & $6 \%$ \\
\hline Total & 83 & $100 \%$ & Total & 36 & $100 \%$ \\
\hline
\end{tabular}

El 51\% de los turistas nacionales indican que realizan sus viajes en familia, un $33 \%$ entre amigos, el $12 \%$ con su pareja y el $5 \%$ solos. Al momento de viajar los turistas extranjeros prefieren hacerlo en compañía de sus amigos representando el $67 \%$, un $22 \%$ en familia, el $6 \%$ en pareja y solos respectivamente.

\section{Conocimiento acerca del agroecoturismo}

Tabla $\mathbf{N}^{\mathbf{0}}$ 7. Conocimiento acerca del agroecoturismo de los turistas nacionales y extranjeros

\begin{tabular}{|c|c|c|c|c|c|}
\hline \multicolumn{3}{|c|}{ Turista nacional } & \multicolumn{3}{c|}{ Turista extranjero } \\
\hline Variables & $\mathrm{N}^{\circ}$ & $\%$ & Variables & $\mathrm{N}^{\circ}$ & $\%$ \\
\hline SI & 50 & $60 \%$ & $\mathrm{SI}$ & 32 & $89 \%$ \\
\hline NO & 33 & $40 \%$ & NO & 4 & $11 \%$ \\
\hline Total & 83 & $100 \%$ & Total & 36 & $100 \%$ \\
\hline
\end{tabular}


Los turistas nacionales indicaron que el $60 \%$ conoce sobre el agroecoturismo y el $40 \%$ desconoce acerca del tema. Los turistas extranjeros indicaron que el $89 \%$ si conoce sobre el agroecoturismo y el $11 \%$ no conoce acerca del tema.

\section{Aceptación del producto agroecoturistico}

Tabla $\mathbf{N}^{\circ}$ 8. Aceptación del producto agroecoturistico de los turistas nacionales y extranjeros

\begin{tabular}{|c|c|c|c|c|c|}
\hline \multicolumn{3}{|c|}{ Turista nacional } & \multicolumn{3}{c|}{ Turista extranjero } \\
\hline Variables & $\mathrm{N}^{\circ}$ & $\%$ & Variables & $\mathrm{N}^{\circ}$ & $\%$ \\
\hline SI & 82 & $99 \%$ & SI & 36 & $100 \%$ \\
\hline NO & 1 & $1 \%$ & NO & 0 & \\
\hline Total & 83 & $100 \%$ & Total & 36 & $100 \%$ \\
\hline
\end{tabular}

Los turistas nacionales aceptan el producto agroecoturistico con un 99\%, mientras que los turistas extranjeros aceptan el 100\% el producto.

\section{Infraestructura de entretenimiento}

Tabla $\mathbf{N}^{\circ} 9$. Infraestructura requerida por los turistas nacionales y extranjeros

\begin{tabular}{|c|c|c|c|c|c|}
\hline \multicolumn{2}{|c|}{ Turista nacional } & \multicolumn{3}{c|}{ Turista extranjero } \\
\hline Variables & $\mathrm{N}^{\circ}$ & $\%$ & Variables & $\mathrm{N}^{\circ}$ & $\%$ \\
\hline Canchas de básquet & 6 & $7 \%$ & Canchas de básquet & 4 & $11 \%$ \\
\hline Canchas de fútbol & 22 & $27 \%$ & Canchas de fútbol & 2 & $6 \%$ \\
\hline Canchas de vóleibol & 6 & $7 \%$ & Canchas de vóleibol & 8 & $22 \%$ \\
\hline Juegos infantiles & 17 & $20 \%$ & Juegos infantiles & 4 & $11 \%$ \\
\hline Piscina temperada & 32 & $39 \%$ & Piscina temperada & 18 & $50 \%$ \\
\hline Total & 83 & $100 \%$ & Total & 36 & $100 \%$ \\
\hline
\end{tabular}

Los turistas nacionales expresaron que el 39\% desea que se implemente una piscina, el $27 \%$ canchas de fútbol mientras que el $7 \%$ expresó que se implementen canchas de básquet y canchas de voleibol respectivamente. Los turistas extranjeros expresaron que el $50 \%$ requiere de la implementación de piscina temperada el 22\% de canchas de vóleibol y el $11 \%$ de canchas de básquet y juegos infantiles respectivamente.

\section{Servicios}

Tabla $\mathbf{N}^{\mathbf{0} 10}$. Servicios de preferencia por los turistas nacionales y extranjeros

\begin{tabular}{|c|c|c|c|c|c|}
\hline \multicolumn{2}{|c|}{ Turista nacional } & \multicolumn{2}{c|}{ Turista extranjero } \\
\hline Variables & $\mathrm{N}^{\circ}$ & $\%$ & Variables & $\mathrm{N}^{\circ}$ & $\%$ \\
\hline Alimentación & 20 & $24 \%$ & Alimentación & 13 & $36 \%$ \\
\hline Alojamiento & 19 & $23 \%$ & Alojamiento & 9 & $25 \%$ \\
\hline Guianza & 10 & $12 \%$ & Guianza & 2 & $6 \%$ \\
\hline Internet & 5 & $6 \%$ & Internet & 2 & $6 \%$ \\
\hline $\begin{array}{c}\text { Tienda para la venta de } \\
\text { productos agroecológicos y } \\
\text { artesanías }\end{array}$ & 15 & $18 \%$ & $\begin{array}{c}\text { Tienda para la venta de } \\
\text { productos agroecológicos y } \\
\text { artesanías }\end{array}$ & 4 & $11 \%$ \\
\hline Transporte & 9 & $11 \%$ & Transporte & 6 & $17 \%$ \\
\hline Televisión con cable & 5 & $6 \%$ & Televisión con cable & 0 & \\
\hline Total & 83 & $100 \%$ & Total & 36 & $100 \%$ \\
\hline
\end{tabular}


Los turistas nacionales expresaron que el $24 \%$ prefiere el servicio de alimentación, el $23 \%$ alojamiento, el $18 \%$ una tienda para la venta de productos agroecológicos y artesanías, el $12 \%$ de guianza, el $11 \%$ de transporte y el 6\% de televisión con cable e internet respectivamente. Los turistas extranjeros expresaron que el $36 \%$ prefiere el servicio de alimentación, el 25\% de alojamiento, el 17\% de trasporte, el 11\% una tienda para la venta de productos agroecológicos y artesanías, el 6\% de guianza e internet respectivamente.

\section{Actividades relacionadas con la agroecología}

Tabla $\mathbf{N}^{\mathbf{0}} \mathbf{1 1}$. Actividades relacionadas con la agroecología preferidas por los turistas nacionales y extranjeros

\begin{tabular}{|c|c|c|c|c|c|}
\hline \multicolumn{3}{|c|}{ Turista nacional } & \multicolumn{3}{|c|}{ Turista extranjero } \\
\hline Variables & $\mathrm{N}^{\circ}$ & $\%$ & Variables & $\mathrm{N}^{\circ}$ & $\%$ \\
\hline Cosecha de productos & 30 & $36 \%$ & Cosecha de productos & 5 & $14 \%$ \\
\hline Elaboración de biol & 8 & $10 \%$ & Elaboración de biol & 4 & $11 \%$ \\
\hline $\begin{array}{c}\text { Observación de los sistemas } \\
\text { de abonamientos y } \\
\text { deshierbe }\end{array}$ & 6 & $7 \%$ & $\begin{array}{c}\text { Observación de los sistemas } \\
\text { de abonamientos y } \\
\text { deshierbe }\end{array}$ & 2 & $6 \%$ \\
\hline Preparación de bokashi & 7 & $8 \%$ & Preparación de bokashi & 4 & $11 \%$ \\
\hline $\begin{array}{l}\text { Uso de microorganismos } \\
\text { antagónicos para el control } \\
\text { de plagas y enfermedades }\end{array}$ & 8 & $10 \%$ & $\begin{array}{l}\text { Uso de microorganismos } \\
\text { antagónicos para el control } \\
\text { de plagas y enfermedades }\end{array}$ & 8 & $22 \%$ \\
\hline $\begin{array}{l}\text { Uso de microorganismos } \\
\text { eficientes para la } \\
\text { degradación de la materia } \\
\text { orgánica }\end{array}$ & 8 & $10 \%$ & $\begin{array}{l}\text { Uso de microorganismos } \\
\text { eficientes para la } \\
\text { degradación de la materia } \\
\text { orgánica } \\
\end{array}$ & 5 & $14 \%$ \\
\hline $\begin{array}{c}\text { Visitas planificadas a } \\
\text { granjas agroecológicas } \\
\text { vecinas } \\
\end{array}$ & 16 & $19 \%$ & $\begin{array}{c}\text { Visitas planificadas a } \\
\text { granjas agroecológicas } \\
\text { vecinas } \\
\end{array}$ & 8 & $22 \%$ \\
\hline Total & 83 & $100 \%$ & Total & 36 & $100 \%$ \\
\hline
\end{tabular}

Los turistas nacionales de acuerdo a las encuestas prefieren realizar cosecha de productos en un 36\%, el 19\% prefiere visitas planificadas a granjas agroecológicas vecinas, el $10 \%$ desean elaborar biol, usar microorganismos antagónicos para el control de plagas y enfermedades y el uso de microorganismos eficientes para la degradación de la materia orgánica, el 8\% prefiere preparar bokashi y el 7\% elige observar los sistemas de abonamientos y deshierbe. Los turistas extranjeros expresaron que el 22\% prefieren las actividades del uso de microorganismos antagónicos para el control de plagas y enfermedades y visitas planificadas a granjas agroecológicas vecinas respectivamente, el $14 \%$ desea realizar cosecha de productos y el uso de microorganismos eficientes para la degradación de la materia orgánica, el 11\% elige la elaboración de biol y la preparación de 
bokashi respectivamente, el 6\% prefiere realizar observación de los sistemas de abonamientos y deshierbe.

\section{Actividades complementarias}

Tabla $\mathbf{N}^{\circ} \mathbf{1 2}$. Actividades complementarias que prefieren realizar los turistas nacionales y extranjeros

\begin{tabular}{|c|c|c|c|c|c|}
\hline \multicolumn{2}{|c|}{ Turista nacional } & \multicolumn{4}{|c|}{ Turista extranjero } \\
\hline Variables & $\mathrm{N}^{\circ}$ & $\%$ & Variables & $\mathrm{N}^{\circ}$ & $\%$ \\
\hline $\begin{array}{c}\text { Avistamiento de aves de la } \\
\text { zona }\end{array}$ & 7 & $8 \%$ & $\begin{array}{c}\text { Avistamiento de aves de la } \\
\text { zona }\end{array}$ & 8 & $22 \%$ \\
\hline Camping & 15 & $18 \%$ & Camping & 7 & $19 \%$ \\
\hline Pesca & 19 & $23 \%$ & Pesca & 3 & $8 \%$ \\
\hline $\begin{array}{c}\text { Práctica de juegos } \\
\text { tradicionales }\end{array}$ & 9 & $11 \%$ & $\begin{array}{c}\text { Práctica de juegos } \\
\text { tradicionales }\end{array}$ & 4 & $11 \%$ \\
\hline $\begin{array}{c}\text { Talleres de educación } \\
\text { ambiental }\end{array}$ & 11 & $13 \%$ & $\begin{array}{c}\text { Talleres de educación } \\
\text { ambiental }\end{array}$ & 4 & $11 \%$ \\
\hline $\begin{array}{c}\text { Visita a páramos y vertientes } \\
\text { de agua }\end{array}$ & 22 & $27 \%$ & $\begin{array}{c}\text { Visita a páramos y } \\
\text { vertientes de agua }\end{array}$ & 10 & $28 \%$ \\
\hline Total & 83 & $100 \%$ & Total & 36 & $100 \%$ \\
\hline
\end{tabular}

Los turistas nacionales expresaron que el $27 \%$ desea visitar a páramos y vertientes de agua, el 23\% desea realizar pesca, el 18\% camping, el 13\% talleres de educación, el 11\% práctica de juegos tradicionales y el 8\% avistamiento de aves de la zona. Los turistas extranjeros expresaron que el 28\% desea visitar a páramos y vertientes de agua, el 22\% avistamiento de aves de la zona, el 19\% camping, el 11\% práctica de juegos tradicionales y talleres de educación y el 8\% pesca.

\section{Pago por producto agroecoturistico}

Tabla $\mathbf{N}^{\mathbf{0}} \mathbf{1 3}$. Pago por producto de los turistas nacionales y extranjeros

\begin{tabular}{|c|c|c|c|c|c|}
\hline \multicolumn{2}{|c|}{ Turista nacional } & \multicolumn{3}{c|}{ Turista extranjero } \\
\hline Variables & $\mathrm{N}^{\circ}$ & $\%$ & Variables & $\mathrm{N}^{\circ}$ & $\%$ \\
\hline$\$ 30$ & 34 & $41 \%$ & $\$ 30$ & 6 & $17 \%$ \\
\hline$\$ 31-\$ 40$ & 36 & $43 \%$ & $\$ 31-\$ 40$ & 13 & $36 \%$ \\
\hline$\$ 41-\$ 50$ & 13 & $16 \%$ & $\$ 41-\$ 50$ & 17 & $47 \%$ \\
\hline Total & 83 & $100 \%$ & Total & 36 & $100 \%$ \\
\hline
\end{tabular}

Los turistas nacionales deciden pagar por el producto agroecoturistico de $\$ 31$ a $\$ 40$ dólares el $43 \%$, el $41 \%$ elige pagar $\$ 30$, y el $16 \%$ elige de $\$ 41$ a $\$ 50$ dólares. Los turistas extranjeros eligen pagar de $\$ 41$ a $\$ 50$ dólares el $47 \%$, el $36 \%$ decide pagar de $\$ 31$ a $\$ 40$ dólares y el $17 \%$ elige pagar $\$ 30$ dólares. 


\section{Medios de información turística usados por el turista nacional y extranjero}

Tabla Nº14. Medios de información

\begin{tabular}{|c|c|c|c|c|c|}
\hline \multicolumn{2}{|c|}{ Turista nacional } & \multicolumn{4}{|c|}{ Turista extranjero } \\
\hline Variables & $\mathrm{N}^{\circ}$ & $\%$ & Variables & $\mathrm{N}^{\circ}$ & $\%$ \\
\hline Agencia de viajes & 6 & $7 \%$ & Agencia de viajes & 2 & $6 \%$ \\
\hline Amigos/Familiares & 5 & $6 \%$ & Amigos/Familiares & 4 & $11 \%$ \\
\hline Guías turísticas & 11 & $13 \%$ & Guías turísticas & 4 & $11 \%$ \\
\hline Prensa & 11 & $13 \%$ & Prensa & 1 & $3 \%$ \\
\hline Radio & 4 & $5 \%$ & Radio & 2 & $6 \%$ \\
\hline Redes sociales & 13 & $16 \%$ & Redes sociales & 4 & $11 \%$ \\
\hline Sitio web & 23 & $28 \%$ & Sitio web & 17 & $47 \%$ \\
\hline Televisión & 10 & $12 \%$ & Televisión & 2 & $6 \%$ \\
\hline Total & 83 & $100 \%$ & Total & 36 & $100 \%$ \\
\hline
\end{tabular}

El 28\% de los turistas nacionales encuestados mencionan que se informan a través de los sitios web, seguido por las redes sociales con un $16 \%$, guías turísticas y prensa con el $13 \%$ respectivamente, mientras que el $12 \%$ lo hace mediante la televisión, el 7\% elige las agencias de viajes, el 6\% a través de amigos y familiares y el $5 \%$ mediante la radio. Los medios de información utilizados por los turistas extranjeros son los sitios web con el $47 \%$, el $11 \%$ usan guía turística, redes sociales y a través de amigos y familiares respectivamente. El 6\% se informa a través de agencia de viajes, radio y televisión, finalmente el 3\% utiliza la prensa.

\section{Perfil del turista}

\section{1) Turista nacional}

El perfil del turista nacional está entre los 26 a 40 años de edad (34\%), el 58\% es de género masculino, la mayoría de los visitantes son de la ciudad de Guayaquil 33\% y de Riobamba el 27\%, el nivel de instrucción es superior $61 \%$.

El 96\% de los encuestados viajan generalmente por distracción y lo realizan en familia el 51\%. El 60\% conoce acerca del agroecoturismo y el 99\% acepta consumir este producto turístico, mientras que el $39 \%$ prefiere piscina templada, el 24\% desea tener el servicio de alimentación, el 23\% de alojamiento y el $18 \%$ una tienda para la venta de productos agroecológicos y artesanías. Las actividades relacionadas a la agroecología que escogen son: la cosecha de productos el 36\%, las visitas planificadas a granjas ecológicas vecinas el $19 \%$. En cuanto a actividades complementarias el $27 \%$ desea visitar páramos y vertientes de agua, el 23\% desea realizar pesca. Están dispuestos a pagar de 31 a 40 dólares por noche de hospedaje y los medios de información que prefieren para informarse son los sitios web $28 \%$ y el $16 \%$ a través de las redes sociales. 


\section{2) Turista extranjero}

El perfil del turista extranjero es de más de los 40 años de edad (50\%), el 53\% es de género masculino, la mayoría de los visitantes son del país de España 39\% y de Alemania el 17\%, el nivel de instrucción es superior $36 \%$.

El 89\% de los encuestados viajan generalmente por distracción y lo realizan entre amigos el 67\%. El 89\% conoce acerca del agroecoturismo y el $100 \%$ acepta consumir este producto turístico, mientras que el 50\% prefiere piscina templada, el 36\% desea tener el servicio de alimentación, el 25\% de alojamiento y el $17 \%$ de transporte. Las actividades relacionadas a la agroecología que escogen son: el uso de microorganismos antagónicos para el control de plagas y enfermedades y visitas planificadas a granjas agroecológica vecinas con el $22 \%$ respectivamente.En cuanto a actividades complementarias, el 28\% desea visitar páramos y vertientes de agua, el 22\% desea realizar avistamiento de aves de la zona. Están dispuestos a pagar de 41 a 50 dólares por noche de hospedaje y el medio de información que escoge para informarse es los sitios web $47 \%$.

\section{Proyección de la demanda y oferta}

Cuadro 5.- Confrontación demanda vs. oferta

\begin{tabular}{|c|c|c|c|c|c|}
\hline \multicolumn{7}{|c|}{ Confrontación Demanda vs Oferta } \\
\hline Año & $\begin{array}{c}\text { Demanda } \\
\text { actual }\end{array}$ & $\begin{array}{c}\text { Demanda } \\
\text { potencial }\end{array}$ & $\begin{array}{c}\text { Oferta } \\
\text { actual }\end{array}$ & $\begin{array}{c}\text { Demanda } \\
\text { insatisfecha }\end{array}$ & $\begin{array}{c}\text { Demanda } \\
\text { objetivo 3\% }\end{array}$ \\
\hline 2014 & 102152 & 101437 & 10871 & 90566 & 2717 \\
\hline 2015 & 115432 & 114624 & 12284 & 102340 & 3070 \\
\hline 2016 & 130438 & 129525 & 13881 & 115644 & 3469 \\
\hline 2017 & 147395 & 146366 & 15686 & 130680 & 3920 \\
\hline 2018 & 166556 & 165390 & 17725 & 147665 & 4430 \\
\hline 2019 & 188208 & 186891 & 20029 & 166862 & 5006 \\
\hline 2020 & 212675 & 211186 & 22633 & 188553 & 5657 \\
\hline
\end{tabular}

Demanda potencial insatisfecha: Para calcular la demanda potencial insatisfecha se utilizó el total de los turistas potenciales, es decir la suma total de la demanda nacional y extranjera proyectada para los próximos 5 años restándole de la oferta potencial de cada año que se demuestra en el cuadro 4. 
Demanda objetivo proyectado en el tiempo

Cuadro 6.- Demanda objetivo

\begin{tabular}{|c|c|c|c|c|}
\hline \multicolumn{5}{|c|}{ Demanda objetivo proyectado } \\
\hline Año & Anual & Mensual & Semanal & Diaria \\
\hline 2014 & 2717 & 226 & 57 & 8 \\
\hline 2015 & 3070 & 255 & 64 & 9 \\
\hline 2016 & 3469 & 289 & 72 & 10 \\
\hline 2017 & 3920 & 326 & 82 & 12 \\
\hline 2018 & 4430 & 369 & 92 & 13 \\
\hline 2019 & 5006 & 417 & 104 & 15 \\
\hline 2020 & 5657 & 471 & 118 & 17 \\
\hline
\end{tabular}

Proyección demanda objetivo: Para calcular la demanda objetivo se consideró el 3\% de la demanda insatisfecha, teniendo en cuenta que este porcentaje permitirá dar inicio con el funcionamiento del proyecto turístico.

\section{- Diseño técnico del producto agroecoturístico}

\section{Localización del proyecto}

Macro localización: La granja integral está localizada en Ecuador, Provincia de Chimborazo, cantón Guano.

Micro localización: El proyecto se desarrollará en la parroquia rural de San Isidro, comunidad Santa Lucia de Tembo.

\section{- $\quad$ Propuesta técnica}

\section{Diseño de servicios turísticos}

$\mathrm{Al}$ ser una empresa que se enfoca en la producción agrícola asociada al turismo y para asegurar la calidad del producto agroecoturístico, se propone trabajar en tres áreas de acción que se distribuirán en las 2 hectáreas que posee la Empresa, con el objetivo de mantener un control total y que a su vez permitan identificar los requerimientos en infraestructura, equipos y menaje que necesitan para asegurar la calidad de servicios y actividades turísticas que se plantea ofertar a los visitantes.

Cuadro 7.- Áreas y sub áreas de la propuesta técnica para el desarrollo del producto agroecoturístico

\begin{tabular}{|c|c|}
\hline Áreas & Sub áreas \\
\hline Área de producción & Frutales y forraje \\
agroecológica & Elaboración de abonos orgánicos y fertilizantes \\
\cline { 2 - 2 } & Manejo de microorganismos antagónicos y eficientes \\
\hline Área de producción pecuaria & Crianza y reproducción de animales \\
\hline Área turística & Servicios turísticos \\
\cline { 2 - 2 } & Esparcimiento y deportes \\
\cline { 2 - 2 } & Camping \\
\hline
\end{tabular}


Diseño de las actividades agroecológicas y turísticas

\begin{tabular}{|c|c|c|}
\hline \multicolumn{3}{|c|}{$\frac{\text { Cuadro 8.- Actividades turísticas y agroecológicas }}{\text { ACTIVIDADES AGROECOLÓGICAS }}$} \\
\hline Actividad & Duración & Breve descripción \\
\hline Cosecha de productos & 3 horas & $\begin{array}{l}\text { El proceso inicia con una charla que oriente al visitante con } \\
\text { respecto al uso de herramientas, y especificaciones técnicas } \\
\text { para no estropear a la planta en el momento de la extracción } \\
\text { del producto, finalizando con el empaquetamiento del } \\
\text { producto. }\end{array}$ \\
\hline Elaboración de biol & 1 hora & $\begin{array}{c}\text { Después de una explicación detallada técnicamente los } \\
\text { visitantes podrán elaborar el biol ( fertilizante orgánico) que } \\
\text { se utiliza para controlar las enfermedades de las plantas } \\
\text { frutales de la propiedad., } \\
\end{array}$ \\
\hline $\begin{array}{l}\text { Observación de los } \\
\text { sistemas de } \\
\text { abonamiento y } \\
\text { deshierbe }\end{array}$ & 1 hora & $\begin{array}{l}\text { Taller práctico en el que los visitantes visualicen y aprendan } \\
\text { acerca de los sistemas de abonamiento y deshierbe, los } \\
\text { cuales s e utilizan frecuentemente en las plantas. }\end{array}$ \\
\hline $\begin{array}{l}\text { Preparación de bokashi } \\
\text { (Abono orgánico) }\end{array}$ & 3 horas & $\begin{array}{l}\text { Consiste en dos fases la primera es una charla explicativa } \\
\text { acerca de los insumos que se utilizan en la elaboración del } \\
\text { abono. La forma de preparación y beneficios del mismo y } \\
\text { la segunda se trata de un taller práctico en el que los } \\
\text { visitantes se involucren en el proceso de elaboración del } \\
\text { bokashi }\end{array}$ \\
\hline $\begin{array}{l}\text { Uso de } \\
\text { microorganismos } \\
\text { antagónicos para el } \\
\text { control de plagas y } \\
\text { enfermedades } \\
\end{array}$ & 1 hora & $\begin{array}{l}\text { Después de una explicación detallada del proceso que se } \\
\text { efectúa para obtener del suelo los microorganismos } \\
\text { antagónicos, se realiza un taller practica que evidencie el } \\
\text { uso de los mismos en los frutales. }\end{array}$ \\
\hline $\begin{array}{c}\text { Uso de } \\
\text { microorganismos } \\
\text { eficientes para la } \\
\text { degradación de la } \\
\text { materia orgánica }\end{array}$ & - & $\begin{array}{l}\text { Se realiza una charla explicativa para conocer el proceso de } \\
\text { preparación de los microorganismos aceleradores de } \\
\text { degradación de la materia orgánica (proceso que se } \\
\text { desarrolla en los laboratorios de Biotecnología de la } \\
\text { Facultad de Recursos Naturales), seguidamente se distingue } \\
\text { la materia orgánica en los proceso de degradación y la que } \\
\text { ya está a lista para su utilización. }\end{array}$ \\
\hline $\begin{array}{l}\text { Visitas planificadas a } \\
\text { granjas ecológicas } \\
\text { vecinas }\end{array}$ & - & $\begin{array}{c}\text { Convivencia con familias de los alrededores de la granja } \\
\text { además se realizaran charlas con granjeros agroecológicos } \\
\text { de la provincia }\end{array}$ \\
\hline \multicolumn{3}{|c|}{ ACTIVIDADES TURÍSTICAS } \\
\hline $\begin{array}{l}\text { Avistamiento de aves } \\
\text { de la zona }\end{array}$ & 2 horas & $\begin{array}{l}\text { En la zona se identifican alrededor de } 13 \text { especies de aves } \\
\text { que son propias de la zona y que poseen una belleza única. }\end{array}$ \\
\hline Camping & 1 noche & $\begin{array}{l}\text { Camping se lo realizara en la parte baja de la propiedad } \\
\text { por poseer un microclima que favorece que el ambiente se } \\
\text { torne un poco más cálido siendo el lugar perfecto para la } \\
\text { pernoctación de los turistas. }\end{array}$ \\
\hline Pesca & 1 hora & $\begin{array}{l}\text { Actividad a realizarse en el tanque reservorio de truchas, } \\
\text { por existir un grupo considerable de especies, la actividad } \\
\text { es corta y no toma mucho tiempo }\end{array}$ \\
\hline $\begin{array}{l}\text { Práctica de juegos } \\
\text { tradicionales }\end{array}$ & $\begin{array}{l}1 \text { hora con } \\
30 \mathrm{~min}\end{array}$ & $\begin{array}{l}\text { A través de la práctica de juegos tradicionales (yoyo, } \\
\text { macateta, quemadas, rayuela, capirotejo, trompo, canicas, } \\
\text { chantas, elástico etc), se contribuirá a la recuperación de } \\
\text { éste patrimonio cultural intangible, a su vez será un espacio } \\
\text { de interacción grupal o familiar. }\end{array}$ \\
\hline Talleres de edu & 1 hora & Los talleres de educación ambiental se realizaran al aire \\
\hline
\end{tabular}




\begin{tabular}{|c|c|c|}
\hline ambiental & & $\begin{array}{c}\text { libre enfocados principalmente en el reciclaje y la } \\
\text { utilización de abonos orgánicos. }\end{array}$ \\
\hline $\begin{array}{l}\text { Visita a páramos y } \\
\text { vertientes de agua }\end{array}$ & 5 horas & $\begin{array}{c}\text { Los páramos y vertientes de agua existentes en San Isidro } \\
\text { se encuentran en comunidades de la parte alta por lo que es } \\
\text { necesario viajar en camioneta y en los lugares en los cuales } \\
\text { el acceso es difícil se realizarán caminatas en las cuales se } \\
\text { visualizará la belleza paisajística }\end{array}$ \\
\hline
\end{tabular}

\section{Definición de itinerarios y paquetes turísticos}

El diseño de los paquetes turísticos se ha elaborado en función al perfil del turista obtenido en el análisis de la demanda, es así que se llegó a definir las preferencias como son recorrido por los atractivos, observación de las formas de cultivo de los productos de la zona, para el mismo se requiere los servicios básicos y una infraestructura adecuada. La oferta de la empresa se basa en satisfacer las expectativas de los turistas, se ha diseñado cuatro paquetes turísticos. Los paquetes incluyen los siguientes servicios: alimentación, hospedaje, transporte y guianza, adicional a esto quienes gusten podrán disfrutar de caminatas y cabalgatas.

\section{Paquete 1}

Paquete modelo de turismo agroecológico

\begin{tabular}{ll}
\hline PAQUETE & TURISMO AGROECOLÓGICO \\
CÓDIGO & PTA-01 \\
DURACIÓN & 2 DIAS Y 1 NOCHE \\
CARÁCTER & AGROECOTURISMO-RECORRIDO \\
DIFICULTAD & FÁCIL \\
DEMANDA & NACIONAL E INTERNACIONAL
\end{tabular}

\section{1) Descripción del paquete}

\section{Riobamba - Santa Lucia de Tembo}

Disfrute la diversidad en producción agrícola y especies menores que posee la granja agroecológica en la que la integración de usted en las actividades están a su disposición; además podrá ser partícipe de las actividades agroecológicas que se desarrollan en la granja, también podrá apreciar la belleza paisajística del majestuoso nevado Chimborazo, conocer la riqueza cultural que existe en este pueblo mestizo y finalmente realizar actividades amigables con el ambiente como es el reciclaje, todo ello basado en promover un turismo sostenible. 
Cuadro 9.-Paquete modelo 1 para turistas nacionales y extranjeros

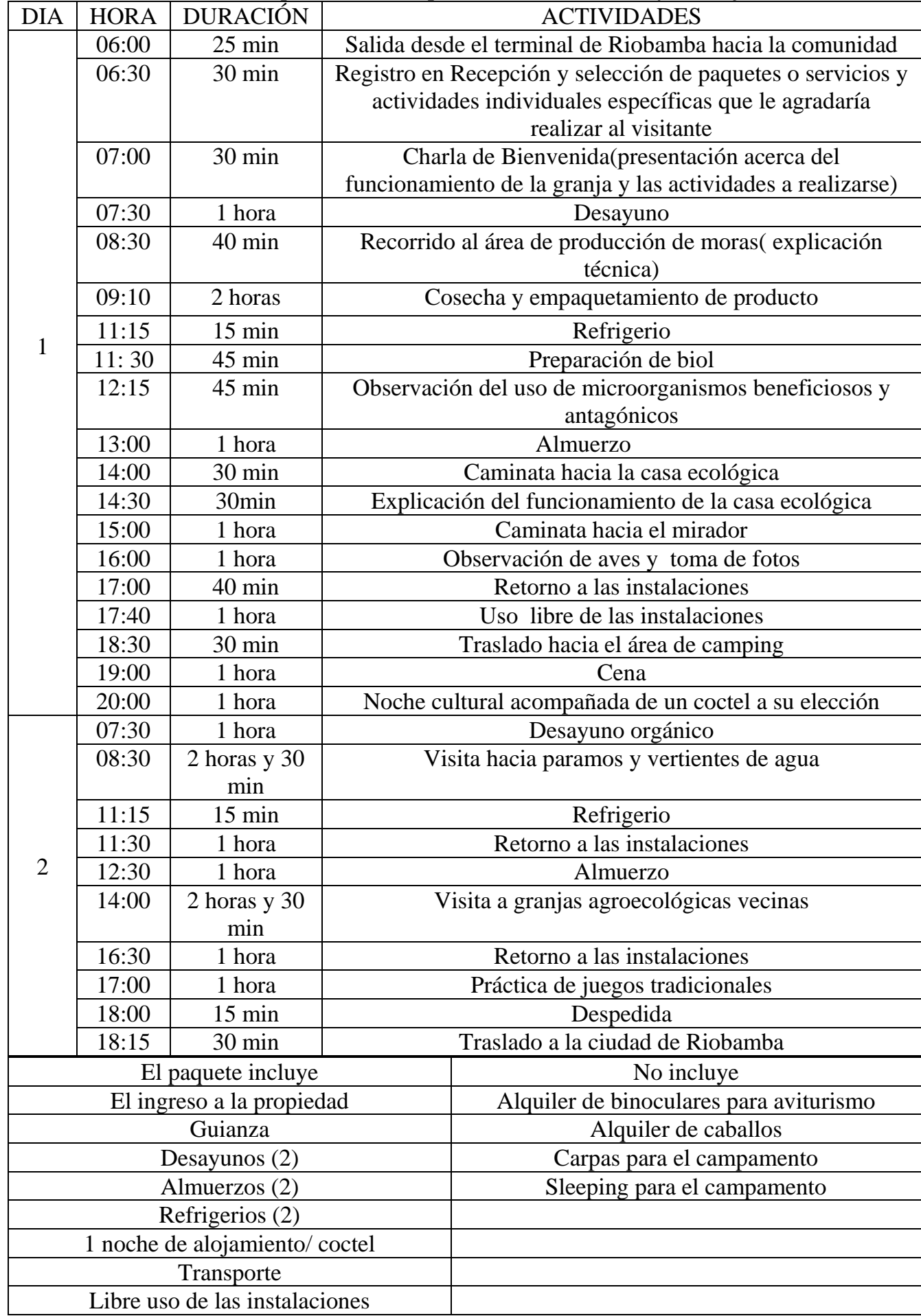


Requerimiento para la visita: Ropa cómoda y abrigada (impermeable, guantes), cámara fotográfica, poncho de aguas, botas de caucho, gorra, protector solar, bebida hidratante.

Que no llevar: Bebidas alcohólicas, armas blancas y de fuego.

\section{Observaciones}

El uso de la piscina estará disponible para grupos de 20 personas en adelante, al igual que la noche cultural con el grupo de danza y el grupo musical.

\section{Paquete 2}

Paquetes modelo de turismo agroecológico

PAQUETE MARAVILLAS DEL CAMPO

CÓDIGO PMC-02

DURACIÓN 3 DIAS Y 2 NOCHES

CARÁCTER AGROECOTURISMO-RECORRIDO

DIFICULTAD FÁCIL

DEMANDA NACIONAL E INTERNACIONAL

\section{1) Descripción del paquete.}

\section{Riobamba - Santa Lucia de Tembo}

Disfrute del contacto con la naturaleza en armonía, conozca los beneficios de practicar la agro ecología, además visite las cristalinas aguas en el páramo del Igualata, disfrute del maravillo paisaje y la flora y fauna de la zona, complemente esta viaje visitando el cantón Guano famoso por su gastronomía y el museo además de sus artesanías, finalmente comparta experiencias con los habitantes de la comunidad al recorrer las granjas agroecológicas vecinas.

Cuadro 10.- Paquete modelo 2 para turistas nacionales y extranjeros

\begin{tabular}{|c|c|c|c|}
\hline DIA & HORA & DURACIÓN & ACTIVIDADES \\
\hline \multirow{12}{*}{1} & 06:00 & $25 \mathrm{~min}$ & Salida desde el terminal de Riobamba hacia la comunidad \\
\hline & 06:25 & $30 \mathrm{~min}$ & $\begin{array}{c}\text { Registro en Recepción y selección de paquetes o servicios y } \\
\text { actividades individuales específicas que le agradaría realizar al } \\
\text { visitante }\end{array}$ \\
\hline & 07:00 & $30 \mathrm{~min}$ & $\begin{array}{c}\text { Charla de Bienvenida( presentación acerca del funcionamiento de la } \\
\text { granja y las actividades a realizarse) }\end{array}$ \\
\hline & 07:30 & 1 hora & Desayuno \\
\hline & 08:30 & $15 \mathrm{~min}$ & Dinámica \\
\hline & $08: 45$ & $\begin{array}{l}1 \text { hora y } 15 \\
\text { min }\end{array}$ & Recorrido al área de producción agrícola ( explicación técnica) \\
\hline & $10: 00$ & $45 \mathrm{~min}$ & $\begin{array}{l}\text { Observación del uso de microorganismos eficientes para la } \\
\text { degradación de materia orgánica ( explicación técnica) }\end{array}$ \\
\hline & $10: 45$ & $15 \min$ & Refrigerio \\
\hline & $11: 00$ & 2 horas & Cosecha y empaquetamiento de los productos agroecológicos \\
\hline & 13:00 & 1 hora & Almuerzo \\
\hline & $14: 00$ & 1 hora & Recorrido al área pecuaria ( explicación técnica) \\
\hline & $15: 00$ & 1 hora y 15 & Preparación de biol \\
\hline
\end{tabular}




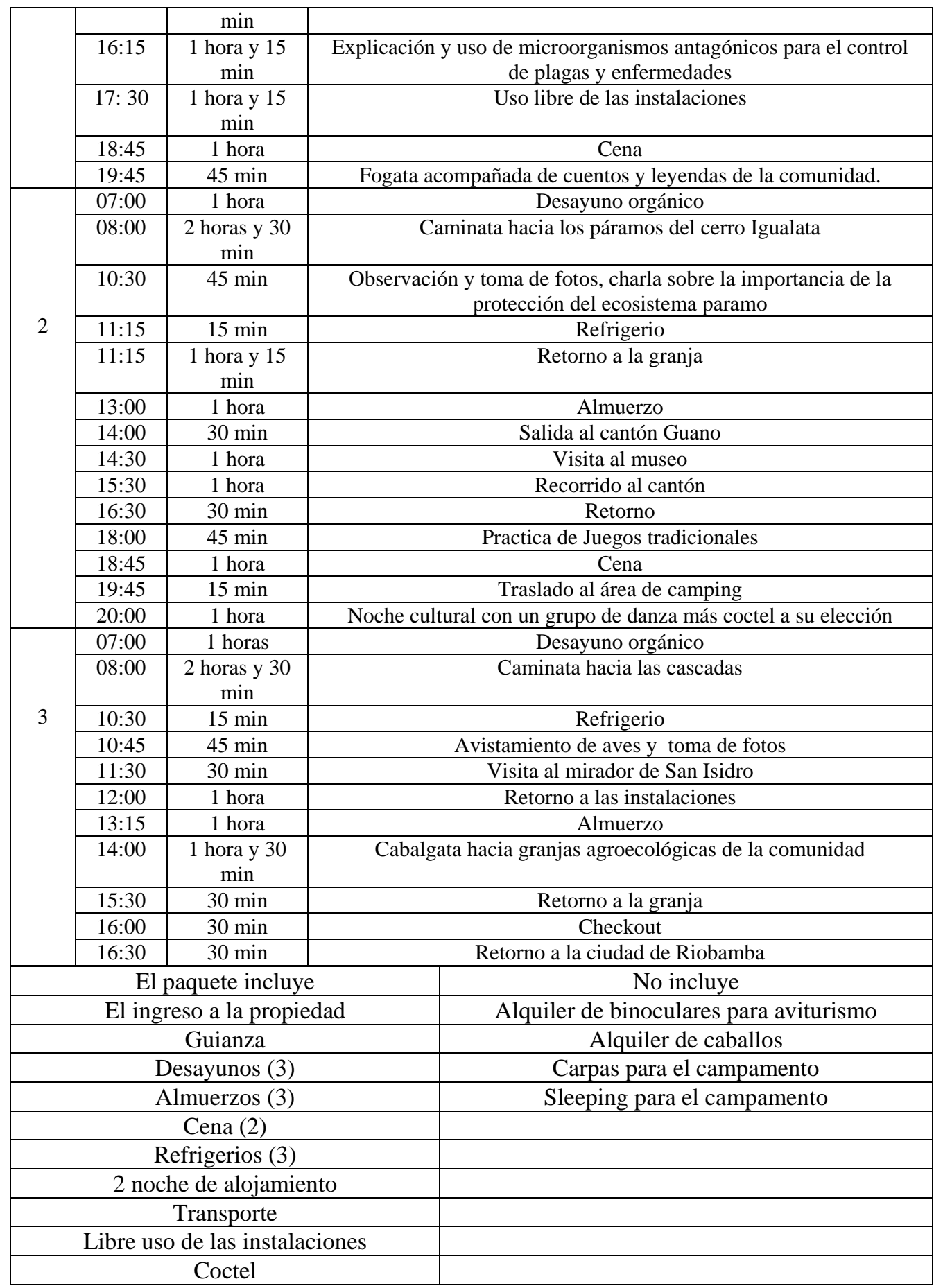




\section{Observaciones}

El uso de la piscina estará disponible para grupos de 20 personas en adelante, al igual que la noche cultural con el grupo de danza y el grupo musical.

\section{Paquete 3}

\section{Paquete modelo de turismo agroecológico para grupos familiares}

PAQUETE CONVIVENCIA FAMILIAR

\section{CÓDIGO PCF-03}

DURACIÓN 2 DIAS Y 1 NOCHES

CARÁCTER AGROECOTURISMO-RECORRIDO

DIFICULTAD FÁCIL

DEMANDA NACIONAL E INTERNACIONAL

\section{1) Descripción del paquete}

\section{Riobamba- Santa Lucía de Tembo}

Disfrute de la pureza del campo en un ambiente acogedor, coseche la producción agroecológica de la granja, disfrute del taller de reciclaje y elaboración de mermeladas, visite las aguas cristalinas de la cascada de San Isidro, observe la belleza paisajística del sector además la flora y fauna. Disfrute de las instalaciones de la granja adecuadas especialmente para el disfrute del turista acompañado de la práctica de juegos tradicionales.

Cuadro 11.- Paquetes modelo para grupos familiares

\begin{tabular}{|c|c|c|}
\hline DÍA & HORA & ACTIVIDADES \\
\hline \multirow{18}{*}{1} & 06:00 & Salida desde el terminal de Riobamba hacia la comunidad \\
\hline & $07: 30$ & $\begin{array}{c}\text { Registro en Recepción y selección de paquetes o servicios y actividades } \\
\text { individuales específicas que le agradaría realizar al visitante }\end{array}$ \\
\hline & 08:00 & $\begin{array}{c}\text { Charla de Bienvenida( presentación acerca del funcionamiento de la } \\
\text { granja y las actividades a realizarse) }\end{array}$ \\
\hline & $08: 30$ & Desayuno \\
\hline & 10:00 & Cosecha y empaquetamiento de los productos agroecológicos \\
\hline & $10: 45$ & Refrigerio \\
\hline & $11: 15$ & Cosecha y empaquetamiento de los productos agroecológicos \\
\hline & $12: 30$ & Almuerzo \\
\hline & 14:00 & Taller de reciclaje, artesanías y pintura de camisetas \\
\hline & 15: 30 & Practica de juegos tradicionales \\
\hline & $16: 30$ & Uso libre de las instalaciones \\
\hline & 19:00 & Cena \\
\hline & $20: 00$ & Noche cultural con un grupo de danza( malvaviscos y chocolate) \\
\hline & 07:00 & Desayuno \\
\hline & 08:00 & Salida a las cascadas \\
\hline & $10: 00$ & Observación y fotografía de las cascadas \\
\hline & $10: 30$ & Refrigerio \\
\hline & $11: 00$ & Visita al mirador de San Isidro \\
\hline
\end{tabular}




\begin{tabular}{|c|c|c|c|}
\hline \multirow[t]{5}{*}{2} & $12: 30$ & & gada a la granja \\
\hline & 13:00 & & Almuerzo \\
\hline & $14: 30$ & Taller de prepar & $\begin{array}{l}\text { rmeladas, manjares y chocolate artesanal( } \\
\text { s), Pesca(adultos) }\end{array}$ \\
\hline & $17: 00$ & & Checkout \\
\hline & 18:00 & & la ciudad de Riobamba \\
\hline \multicolumn{3}{|c|}{ El paquete incluye } & No incluye \\
\hline \multicolumn{3}{|c|}{ El ingreso a la propiedad } & Alquiler de binoculares para aviturismo \\
\hline \multicolumn{3}{|c|}{ Guianza } & Alquiler de caballos \\
\hline \multicolumn{3}{|c|}{ Desayunos (2) } & Carpas para el campamento \\
\hline \multicolumn{3}{|c|}{ Almuerzos (2) } & Sleeping para el campamento \\
\hline \multicolumn{4}{|c|}{ Cena (2) } \\
\hline \multicolumn{4}{|c|}{ Refrigerios (2) } \\
\hline \multicolumn{4}{|c|}{1 noche de alojamiento } \\
\hline \multicolumn{4}{|c|}{ Transporte } \\
\hline \multirow{2}{*}{\multicolumn{3}{|c|}{$\begin{array}{c}\text { Libre uso de las instalaciones } \\
\text { Coctel }\end{array}$}} & \\
\hline & & & \\
\hline
\end{tabular}

\section{Observaciones}

El uso de la piscina estará disponible para grupos de 20 personas en adelante, al igual que la noche cultural con el grupo de danza y el grupo musical.

\section{Paquete 4}

\section{Paquetes modelo de turismo agroecológico para productores agrícolas}

PAQUETE COMPARTIENDO SABERES

CÓDIGO PCS-04

DURACIÓN 1 DIA

CARÁCTER AGROECOTURISMO-RECORRIDO

DIFICULTAD FÁCIL

DEMANDA SOCIOS “ASOPROCH”

\section{1) Descripción del paquete}

\section{Riobamba- Santa Lucía de Tembo}

Disfrute de la pureza del campo en un ambiente acogedor, coseche la producción agroecológica de la granja, disfrute del taller de reciclaje y elaboración de mermeladas, visite las aguas cristalinas de la cascada de San Isidro, observe la belleza paisajística del sector además la flora y fauna. Disfrute de las instalaciones de la granja adecuadas especialmente para el disfrute del turista acompañado de la práctica de juegos tradicionales. 
Cuadro 12.- Paquete modelo para agricultores

\begin{tabular}{|c|c|c|c|}
\hline DÍA & HORA & & ACTIVIDADES \\
\hline \multirow{13}{*}{1} & 06:00 & \multicolumn{2}{|c|}{ Salida desde el terminal de Riobamba hacia la comunidad } \\
\hline & 07:30 & \multicolumn{2}{|c|}{$\begin{array}{c}\text { Registro en Recepción y selección de paquetes o servicios y } \\
\text { actividades individuales específicas que le agradaría realizar al } \\
\text { visitante }\end{array}$} \\
\hline & 08:00 & \multicolumn{2}{|c|}{$\begin{array}{l}\text { Charla de Bienvenida( presentación acerca del funcionamiento de la } \\
\text { granja y las actividades a realizarse) }\end{array}$} \\
\hline & 08:30 & \multicolumn{2}{|r|}{ Desayuno } \\
\hline & 09:30 & \multicolumn{2}{|r|}{ Preparación de bioles } \\
\hline & 10: 30 & \multicolumn{2}{|c|}{$\begin{array}{l}\text { Utilización de organismos beneficios y antagónicos para control } \\
\text { biológico }\end{array}$} \\
\hline & $11: 30$ & \multicolumn{2}{|r|}{ Refrigerio } \\
\hline & $12: 00$ & \multicolumn{2}{|c|}{ Cosecha y empaquetamiento de los productos agroecológicos } \\
\hline & 13:00 & \multicolumn{2}{|r|}{ Almuerzo } \\
\hline & $14: 00$ & \multicolumn{2}{|c|}{ Cosecha y empaquetamiento de los productos agroecológicos } \\
\hline & 15: 00 & \multicolumn{2}{|c|}{ Practica de juegos tradicionales } \\
\hline & $16: 00$ & \multicolumn{2}{|c|}{ Uso libre de las instalaciones } \\
\hline & $18: 00$ & \multicolumn{2}{|r|}{ Despedida } \\
\hline \multicolumn{3}{|c|}{ El paquete incluye } & No incluye \\
\hline \multicolumn{3}{|c|}{ El ingreso a la propiedad } & Alquiler de binoculares para aviturismo \\
\hline \multicolumn{3}{|c|}{ Guianza } & Alquiler de caballos \\
\hline \multicolumn{4}{|c|}{ Desayunos (1) } \\
\hline \multicolumn{4}{|c|}{ Almuerzos (1) } \\
\hline \multicolumn{4}{|c|}{ Refrigerios (1) } \\
\hline \multicolumn{4}{|c|}{ Transporte } \\
\hline \multicolumn{3}{|c|}{ Libre uso de las instalaciones } & \\
\hline
\end{tabular}

\section{Observaciones}

El uso de la piscina estará disponible para grupos de 20 personas en adelante.

\section{Conclusion}

La parroquia posee un patrimonio natural (50\%) y cultural (50\%) con potencialidad turística reflejada en la variedad de atractivos turísticos, principalmente por aquellos valorados con jerarquía II ( rio Guano, Iglesia de San Isidro, plantación de mora cultivada agroecológicamente, cascadas de San Isidro, páramo de Igualata) lo cual convierte en un destino ideal para quienes buscan turismo de naturaleza, caracterizado por la producción agroecológica responsable con el ambiente y con el consumidor.

De los turistas extranjeros el $36 \%$ de las personas encuestadas desearía contar con el servicio de alimentación, mientras que el 25\% con el servicio de hospedaje, un $17 \%$ se mostró interesado por el servicio de transporte, además los turistas se ven interesados en la implementación de una tienda para la venta de productos agroecológicos y artesanías en un 11\%, el servicio de guianza e internet es requerido en un 6\%. En cuanto a los 
turistas nacionales el $24 \%$ de las personas encuestadas desearía contar con el servicio de alimentación, mientras que el 23\% con el servicio de hospedaje, un 18\% se mostró interesado por la en la implementación de un atienda para la venta de productos agroecológicos y artesanías, un 11\% ve necesario el servicio de transporte, y en un porcentaje similar 6\% los turistas requieren el servicio de tv cable e internet.

El producto agroecoturístico tiene una gran aceptación en el mercado, cuyos datos se reflejan en el estudio de mercado con un 100\% por parte de los turistas extranjeros y un $99 \%$ por turistas nacionales, determinando que las instalaciones de la granja tiene capacidad para acoger a un 3\% (3070) anual de la demanda insatisfecha que llega a la provincia.

El diseño del producto agroecoturístico se realizó en base al estudio de mercado y principalmente de los atractivos que alcanzaron mayor jerarquía, de lo cual se obtuvo la propuesta de 4 paquetes los mismos que fueron diseñados cubriendo las necesidades básicas del consumidor y que se ofrecerán directamente al turista, circularan en la extensión de la granja y la parroquia, considerando recursos inutilizados hasta esta propuesta, permitiendo la diversificación de sitios turísticos para el cantón y la provincia.

\section{References:}

1. Ávila, R; Barrado, D. (2005). Nuevas tendencias en el desarrollo de destinos turísticos: marcos conceptuales y operativos para su planificación y gestión. Cuadernos de Turismo (15) pagina 27-43. Recuperado de http://www.redalyc.org/articulo.oa?id=39801502

2. Blanco. M, Riveros H. (2010). El agroturismo como diversificación de la actividad agropecuaria y agroindustrial; conceptos, instrumentos y casos de cooperación técnica. Instituto Interamericano de Cooperación para la Agricultura-IICA. Consultado el 24 de junio del 2016. Disponible en http://www.pa.gob.mx/publica/rev_49/An\%C3\%A1lisis/el_agroturis mo_como_-_Marvin_Blanco_M..pdf

3. Budowski, G. (2001). Modalidades agroturísticas y sus limitaciones. Consultado el 26 de julio del 2016. Disponible en: http://cro.ots.ac.cr/rdmcnfs/datasets/biblioteca/pdfs/nbina-6228.pdf

4. Cárdenas, F. (2001). Evolución del turismo. Comercialización del Turismo. Determinación y Análisis del Mercado. 3ra edición. Editorial Trillas. México.

5. Crosby, A; Moreda, A. (1996). Desarrollo y gestión del turismo en áreas rurales y naturales. Centro Europeo de Formación Ambiental y Turística. Madrid-España. 
6. Instituto Nacional de Patrimonio Cultural-INPC. (2011). Instructivo para fichas de registro e inventario del Patrimonio Cultural Inmaterial. Quito-Ecuador. Ediecuatorial.

7. Ministerio de Turismo-MINTUR. (2004). Metodología para inventarios de atractivos turísticos. Quito. Consultado el 01 de Marzo de 2015. Recuperado de http://www.mintur.gov.ec

8. Molina, S. (2004). Evolución del turismo. Turismo y Ecología. Serie Turismo Trillas. 2da edición. Editorial Trillas. México.

9. Moreno M. Coromoto M. (2010). Turismo y producto turístico: Evolución, conceptos, componentes y clasificación. http://www.saber.ula.ve/bitstream/123456789/33973/1/articulo10.pdf

10. Riveros, H; Blanco, M. (2003). El agroturismo, una alternativa para revalorizar la agroindustria rural como mecanismo de desarrollo local. PRODAR. Lima, Perú, Instituto Interamericano de Cooperación para la Agricultura. 30 p.

11. Secretaria Nacional de Planificación y Desarrollo. (2015). Plan Estratégico SENPLADES 2014-2017. Consultado el 19 de julio del 2015. Recuperado de: http://www.planificacion.gob.ec/wpcontent/uploads/downloads/2015/10/Plan-Estrategico-Senplades2014-2017.pdf

12. Tierra, P. (2012). Texto Básico de Planificación Territorial. Escuela Superior Politécnica de Chimborazo. Riobamba-Ecuador

13. UWNTO. (2016). Barómetro OMT de turismo mundial: El turismo internacional continúa creciendo por encima de la media en los cuatro primeros meses del 2016. Comunicado de prensa $\mathrm{N}^{\circ} 14$. Consultado el 30 de julio del 2016. Disponible en: http://cf.cdn.unwto.org/sites/all/files/pdf/unwto_barom16_04_july_ex cerpt_.pdf

14. Vidal, M. (2004). Tierra de Gracia y Buenos Negocios. Vol. XI. Ediciones IESA-Aniversario. Venezuela

15. Zumbado F. (2007). El agroecoturismo en Costa Rica: Propuestas para maximizar el desarrollo de la actividad agroecoturística en el país. Maestría Interdisciplinaria en Gestión Ambiental y Ecoturismo. Universidad de Costa Rica. Consultado el 22 de junio del 2016. Disponible en: file://C:/Users/user/Downloads/PDF\%20F\%C3\%A9lix\%20Zumbado .pdf

16. MAE-Ministerio del Ambiente del Ecuador. (2016). Sistema Nacional de Áreas Protegidas- SNAP. Consultado el 27 de julio del 2016. Recuperado de: http://areasprotegidas.ambiente.gob.ec/infosnap 